\title{
Evaluation of the antibacterial and antibiofilm activity of probiotic bacteria against causative bacterial pathogens of dental caries
}

Parastoo Jafarzade, Hadi Sedigh Ebrahim-Saraie², Shahab Rezaie3, Elham Maghareh Abed4, Majid Ahangari3, Golbarg Rezaei4, Kouroush Delpasand33, Tofigh Yaghubi Kalurazi³, Meysam HasannejadBibalan ${ }^{2, *}$

\author{
'Department of Physiology, School of Medicine, Guilan University of Medical Sciences, Rasht, Iran \\ 2Department of Microbiology, School of Medicine, Guilan University of Medical Sciences, Rasht, Iran \\ 3Razi Clinical Research Development Unit, Razi Hospital, Guilan University of Medical Sciences, Rasht, Iran \\ 4Department of Microbiology, Faculty of Biological Sciences, Islamic Azad University North Tehran Branch, Tehran, Iran
}

\begin{abstract}
The most important factor in tooth decay and periodontal disease is the attachment of oral bacteria, especially streptococci, to different levels of the mouth and teeth. Therefore, by changing the microbial ecology in the mouth using probiotic producing bacteria, we can help prevent tooth decay and periodontal infections. This study aimed to evaluate the antibacterial and antibiofilm activities of probiotic producing Lactobacillus against several streptococci that cause tooth decay. Antimicrobial activity and minimal inhibitory concentration (MIC) of probiotic lactobacilli was determined by disk diffusion method and standard broth microdilution, respectively. Antibiofilm activity was assayed by a microtiter-plate screening method. The five isolates of Lactobacillus strains with probiotic properties include Lactobacillus plantarum, Lactobacillus rhamnosus, Lactobacillus reuteri, Lactobacillus fermentum, and Lactobacillus brevis were tested against Streptococcus mutans and Streptococcus sanguinis. Most of tested Lactobacillus strain at concentrations above $125 \mu \mathrm{g} / \mathrm{mL}$ showed antibacterial properties. Also, examination of the MICs showed that probiotic bacteria had greater effects on $S$. sanguinis. While, the tested probiotic bacteria did not show a significant antibiofilm effect. Our results suggest that lactobacilli with potential probiotic properties can be effective used for eliminating oral streptococcal colonization.
\end{abstract}

Keywords: Probiotic, Streptococcus mutans, Streptococcus sanguinis, Antibiofilm, Antibacterial

\section{Introduction}

Oral infections are the most common and expensive forms of human infections. Dental caries and periodontal disease occur in more than half of the population [1]. Changing microbial ecology as a mechanism to prevent dental caries is an important issue. Also, the increase of bacterial resistance to antibiotics needs the looking for newer and better antimicrobials agents for the prevention and treatment of oral disease $[2,3]$.

Streptococcus mutans can convert sucrose into water-soluble glucan (WIG), which is one of the most important components of oral biofilm. [4]. In addition, they are important and potent pathogens of tooth decay that occur in dental plaque after adhesion to the tooth surface due to the accumulation of lactic acid,

\section{*Corresponding author:}

Meysam Hasannejad-Bibalan, Ph.D

Department of Microbiology, School of Medicine,

Guilan University of Medical Sciences, Rasht, Iran

(C) The Author(s) 2021

Tel/Fax: +98 1333690006

Email: : meysam_hasannejad@yahoo.com, hasannejad@gums.ac.ir

https://orcid.org/o0oo-0002-9402-098X

Received: March, 29, 2021
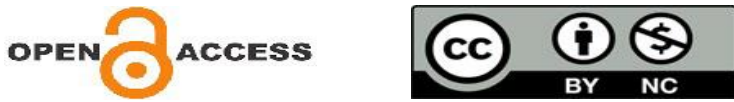

Accepted: July, 16, 2021 
therefore, acid producers are considered to be likely to cause tooth decay [5]. Although streptococci such as Streptococcus sanguinis and Streptococcus salivarius have been reported to produce organic acid, their acid tolerance is weaker than that of mutant streptococci, limiting the contribution of these oral streptococci to caries [6]. The presence of $S$. sanguinis in the oral cavity may also be the result of moderate caries in children [7].

The use of probiotics as a new method to eliminate pathogenic bacteria in the oral cavity can be considered. The use of probiotics is a promising way to fight infections with the help of beneficial bacteria and replace them with pathogenic microorganisms [8]. Mutans streptococci are one of the most important cariogenic bacteria and various in vitro studies have shown that Lactobacillus rhamnosus and Lactobacillus paracasei can reduce the number of mutans streptococci significantly [9]. Different species of bacteria have been introduced as probiotics, the most common of which are Lactobacillus and Bifidobacterium. Today, the benefits of using probiotics in systemic diseases, especially gastrointestinal diseases, have been identified [10]. However, there are limited studies in this field and their role in maintaining oral health needs further investigation.

Probiotics can work through several mechanisms; Probiotic bacteria inhibit the colonization of pathogenic bacteria by colonizing the intestinal tract, binding to each other, using nutrients in the body before being consumed by pathogenic microorganisms, and producing toxins [11]. Other potential benefits of probiotics in host health include reduced susceptibility to infections, prevention and treatment of allergic manifestations, treatment of lactose intolerance, regulation of blood pressure and serum cholesterol, treatment of cardiovascular disease and cancer, it also eliminates the side effects of overuse of antibiotics (such as diarrhea) and especially the emergence of bacterial resistance [12].

Lactobacilli have no role in initiating the caries process and are mostly associated with dentin caries and are present at the site of carious lesion progression [13]. It has been shown that salivary streptococci are significantly reduced immediately after the end of daily use of the probiotic Lactobacillus [14]. However, in people with advanced dentin caries, consumption of probiotic products may lead to an increase in lactobacilli in the carious lesion and further progression of caries [15]. In this study, we aimed to evaluate the antibacterial and antibiofilm activity of probiotic bacteria against streptococci that cause tooth decay.

\section{Materials and Methods}

\subsection{Bacterial strains}

In a study conducted at Guilan University of Medical Sciences (ethics code IR.GUMS.REC.1399.343), 42 isolates of Lactobacillus which was previously isolated from human fecal samples were studied. Of these, the results of 5 strains which belonged to Lactobacillus plantarum, $L$. rhamnosus, Lactobacillus reuteri, Lactobacillus fermentum, and Lactobacillus brevis species were more promising and can be considered as potential probiotics sources for functional products. Two strains of bacteria including $S$. mutans ATCC 35668, $S$. sanguinis ATCC10556, were used. The strains were recovered from stocks by cultured overnight at $37^{\circ} \mathrm{C}$.

\subsection{Determination of antimicrobial activity}

To investigate the antibacterial effect of probiotic producing Lactobacillus strains, microbial susceptibility testing by the well-diffusion method was used. McFarland 0.5 standard concentration was obtained from the bacteria and cultured on Mueller Hinton agar enriched with $5 \%$ sheep blood using a swap. In the next step, wells with a diameter of $6 \mathrm{~mm}$ were created on this medium, and then supernatant without cells of Lactobacillus strains was added to each well $(62.5-500 \mu \mathrm{g} / \mathrm{mL})$. Finally, the plates were incubated for 24 hours at $37^{\circ} \mathrm{C}$ and then the diameter of the growth inhibition zone was measured [16].

\subsection{Determining the minimal inhibitory concentration (MIC)}

Probiotic bacteria MICs were determined by standard broth microdilution method based on the clinical and laboratory standards institute (CLSI) guidelines [17]. Muller Hinton was used to determine the MIC for the studied strains. To evaluate the inhibitory effects of probiotics on bacterial growth, each 96-well microplate was filled with a concentration range ( 15.6 to $500 \mu \mathrm{g} / \mathrm{mL}$ ). After 24 hours of incubation at $37^{\circ} \mathrm{C}$, the wells were examined for microbial growth and the lowest concentration at 
which no growth was observed was considered as MIC.

\subsection{Biofilm formation assay}

Probiotic bacteria were added to the microtiter plate wells and incubated at $37^{\circ} \mathrm{C}$ for $48 \mathrm{~h}$. After staining with crystal violet and adding ethanol, the absorbance was measured at $570 \mathrm{~nm}$ [18]. The tests were done at least three times.

\subsection{Statistical Analyses}

In this study, the obtained results were entered into SPSS software ver.25. To describe quantitative variables from the mean and standard deviation and for qualitative variables numbers and percentages were used.

\section{Results}

The diameter of the inhibition zone was measured by the well-diffusion method at different concentrations (Supplementary figure 1) that was estimated between 10 and $16 \mathrm{~mm}$ (Table 1). Most isolates have an inhibition zone at concentrations above $125 \mu \mathrm{g} / \mathrm{mL}$.

The MICs values of the five Lactobacillus isolates against $S$. sanguinis and $S$. mutans bacteria were estimated at 62.5 to $250 \mu \mathrm{g} / \mathrm{mL}$ and 125 to $500 \mu \mathrm{g} / \mathrm{mL}$, respectively. The detailed results of MIC of were shown in Table 2.

Probiotic bacteria could not significantly inhibit the formation of biofilms in the suspension tested at concentrations of 62.5 to $500 \mu \mathrm{g} / \mathrm{mL}$ (data not shown).
The minimum inhibitory concentration for tested bacteria was $125 \mu \mathrm{g} / \mathrm{mL}$. At this concentration, the diameter of the inhibition zone was estimated to be approximately $10 \mathrm{~mm}$.

Consistent with our results in a study conducted by Rayani et al. to compare the effect of probiotic and regular buttermilk on two common oral microorganisms, S. mutans and Enterococcus faecalis, thier results indicate a significant differencein the MIC of the two types of probiotic dough used against tested bacteria [19].

Our current results in a laboratory study indicate that probiotic lactobacilli affect the growth and inhibition of oral streptococci. This finding is in agreement with the results of a study that showed that consumption of yogurt or probiotic drinks can significantly reduce the level of $S$. mutans [20, 21]. The results of a study in Denmark showed that $L$. rhamnosus significantly reduced the risk of caries. Therefore, milk containing probiotic bacteria may have beneficial effects on children's dental health [22]. Several studies have shown that the amount of $S$. mutans in saliva decreases significantly immediately after the end of daily consumption of probiotic lactobacilli [23, 24].

Previously, a study conducted in Ahvaz (Southwestern Iran) to investigate the effect of consumption of probiotic yogurt containing Bifidobacterium lactis $\mathrm{B} 12$ on $S$. mutans and lactobacilli in students with early stages of tooth decay, contrary to the results of our study, in which the studied probiotics had little effect on the removal of bacterial biofilm, a significant decrease in biofilm was observed in the intervention group compared to the

Table 1. The diameter of the inhibition zone in different concentration of probiotic isolates

\begin{tabular}{lcccccccc}
\hline & \multicolumn{4}{c}{ S. sanguinis } & \multicolumn{4}{c}{ S. mutans } \\
Bacteria & $500 \mu \mathrm{g} / \mathrm{ml}$ & $250 \mu \mathrm{g} / \mathrm{ml}$ & $125 \mu \mathrm{g} / \mathrm{ml}$ & $62.5 \mu \mathrm{g} / \mathrm{ml}$ & $500 \mu \mathrm{g} / \mathrm{ml}$ & $250 \mu \mathrm{g} / \mathrm{ml}$ & $125 \mu \mathrm{g} / \mathrm{ml}$ & $62.5 \mu \mathrm{g} / \mathrm{ml}$ \\
\hline L. plantarum & $14 \mathrm{~mm}$ & $12 \mathrm{~mm}$ & 0 & 0 & $12 \mathrm{~mm}$ & $11 \mathrm{~mm}$ & 0 & 0 \\
\hline L. rhamnosus & 14 & 12 & 11 & 0 & 15 & 12 & 10 & 0 \\
\hline L. reuteri & 15 & 12 & 10 & 0 & 14 & 12 & 10 & 0 \\
\hline L. fermentum & 12 & 12 & 10 & 0 & 11 & 0 & 0 & 0 \\
\hline L. brevis & 16 & 13 & 10 & 10 & 14 & 11 & 10 & 0
\end{tabular}

\section{Discussion}

In the present study, the antibacterial and antibiofilm effects of native probiotic bacteria on cariescausing bacteria and dental plaque were measured. control group [25]. Another study conducted in China examined the effect of probiotic lactobacilli on $S$. mutans and the development of biofilms in children with severe caries. Their results showed Lactobacillus 
casei significantly reduced the number of $S$. mutans, $S$. sanguinis, and all bacteria in mixed biofilms compared to the control group [26]. As the main limitations of the present study, a narrow range of tested bacteria and the lack of toxicity evaluation should be acknowledged.

Table 2. MIC of probiotic bacteria on both Streptococcus strains

\begin{tabular}{lcc}
\hline \multirow{2}{*}{ Bacteria } & \multicolumn{2}{c}{ MIC } \\
\cline { 2 - 3 } & S. sanguinis & S. mutans \\
\hline L. plantarum & $250 \mu \mathrm{g} / \mathrm{ml}$ & $250 \mu \mathrm{g} / \mathrm{ml}$ \\
\hline L. rhamnosus & $125 \mu \mathrm{g} / \mathrm{ml}$ & $125 \mu \mathrm{g} / \mathrm{ml}$ \\
\hline L. reuteri & $250 \mu \mathrm{g} / \mathrm{ml}$ & $250 \mu \mathrm{g} / \mathrm{ml}$ \\
\hline L. fermentum & $250 \mu \mathrm{g} / \mathrm{ml}$ & $500 \mu \mathrm{g} / \mathrm{ml}$ \\
L. brevis & $62.5 \mu \mathrm{g} / \mathrm{ml}$ & $125 \mu \mathrm{g} / \mathrm{ml}$ \\
\hline
\end{tabular}

The results of the study showed that probiotic bacteria with potential antibacterial properties against bacteria that cause tooth decay can be used to prevent dental caries. Probiotics will be used as a new method in the future due to their cost-effectiveness and fewer side effects compared to other antibacterial compounds. However, our local probiotics did not show a significant effect on preventing biofilms formation.

\section{Supplementary files}

Supplementary file 1 .

\section{Author contribution}

HS, MA, MH: conceived the study. HS, SHR, MA, GR, KD: participated in the design of the study and performed the statistical analysis. PJ, HS, SHR, EM, GR, TY, MH: interpreted the data. HS, MH, MA, SHR: obtained ethical clearance and permission for study. HS, MA, HS: Supervised data collectors. PJ, HS, SHR, EM, GR, KD, TY, MH: Drafting the article or revisiting it critically for important intellectual content. HS, MA, $\mathrm{MH}$ were project leaders and primary investigators of the study. All authors read and approved the final manuscript.

\section{Conflict of Interests}

There is no conflict of interest.

\section{Ethical declarations}

The study protocol was approved by the Guilan University of Medical Sciences. The ethical approval code is IR.GUMS.REC.1399.343.

\section{Financial support}

Self-funding.

\section{References}

1. Caglar E, Kargul B, Tanboga I. Bacteriotherapy and probiotics' role on oral health. Oral Dis. 2005; 11(3):131-7.

2. Cudic M, Condie BA, Weiner DJ, Lysenko ES, Xiang ZQ, Insug $\mathrm{O}$, et al. Development of novel antibacterial peptides that kill resistant isolates. Peptides. 2002; 23(12):2071-83.

3. Nicolas G, Auger I, Beaudoin M, Hallé F, Morency H, LaPointe $\mathrm{G}$, et al. Improved methods for mutacin detection and production. J Microbiol Methods. 2004; 59(3):351-61.

4. Hamada S, Slade HD. Biology, immunology, and cariogenicity of Streptococcus mutans. Microbiol Rev. 1980; 44(2):331-84.

5. Terai T, Okumura T, Imai S, Nakao M, Yamaji K, Ito M, et al. Screening of Probiotic Candidates in Human Oral Bacteria for the Prevention of Dental Disease. PLoS One. 2015; 10(6):e0128657. 6. Douglas CW, Heath J, Hampton KK, Preston FE. Identity of viridans streptococci isolated from cases of infective endocarditis. J Med Microbiol. 1993; 39(3):179-82.

7. Ge Y, Caufield PW, Fisch GS, Li Y. Streptococcus mutans and Streptococcus sanguinis colonization correlated with caries experience in children. Caries Res. 2008; 42(6):444-8.

8. Mahasneh SA, Mahasneh AM. Probiotics: A Promising Role in Dental Health. Dent J (Basel). 2017; 5(4):26.

9. Fernández CE, Giacaman RA, Tenuta LM, Cury JA. Effect of the Probiotic Lactobacillus rhamnosus LB21 on the Cariogenicity of Streptococcus mutans UA159 in a Dual-Species Biofilm Model. Caries Res. 2015; 49(6):583-90.

10. Fijan S. Microorganisms with claimed probiotic properties: an overview of recent literature. Int J Environ Res Public Health. 2014; 11(5):4745-67.

11. Hart AL, Lammers K, Brigidi P, Vitali B, Rizzello F, Gionchetti $\mathrm{P}$, et al. Modulation of human dendritic cell phenotype and function by probiotic bacteria. Gut. 2004; 53(11):1602-9.

12. Amara AA, Shibl A. Role of Probiotics in health improvement, infection control and disease treatment and management. Saudi Pharm J. 2015; 23(2):107-14.

13. Becker MR, Paster BJ, Leys EJ, Moeschberger ML, Kenyon SG, Galvin JL, et al. Molecular analysis of bacterial species associated with childhood caries. J Clin Microbiol. 2002; 4O(3):1001-9.

14. Busscher HJ, Mulder AF, van der Mei HC. In vitro adhesion to enamel and in vivo colonization of tooth surfaces by Lactobacilli from a bio-yoghurt. Caries Res. 1999; 33(5):403-4.

15. Badet MC, Richard B, Dorignac G. An in vitro study of the pHlowering potential of salivary lactobacilli associated with dental caries. J Appl Microbiol. 2001; 90(6):1015-8.

16. Chen CC, Lai CC, Huang HL, Huang WY, Toh HS, Weng TC, et al. Antimicrobial Activity of Lactobacillus Species Against Carbapenem-Resistant Enterobacteriaceae. Front Microbiol. 2019; 10:789. 
17. CLSI, Performance Standards for Antimicrobial Susceptibility Testing; 30th ed. CLSI supplement M100. Wayne, PA: Clinical and Laboratory Standards Institute; 2020.

18. Pitts B, Hamilton MA, Zelver N, Stewart PS. A microtiter-plate screening method for biofilm disinfection and removal. $\mathrm{J}$ Microbiol Methods. 2003; 54(2):269-76.

19. Rayani A, Ahanjan M, Goli HR, Naderi fard N, zamanzdeah M. Comparing the Effect of Probiotic and Non-probiotic Yogurt Drinks on Two Common Oral Microorganisms: An In Vitro Study. J Mazandaran Univ Med Sci. 2020; 30(185):33-40.

20. Nozari A, Motamedifar M, Seifi N, Hatamizargaran Z, Ranjbar MA. The Effect of Iranian Customary Used Probiotic Yogurt on the Children's Salivary Cariogenic Microflora. J Dent (Shiraz). 2015; 16(2):81-6.

21. Ashwin D, Ke V, Taranath M, Ramagoni NK, Nara A, Sarpangala M. Effect of Probiotic Containing Ice-cream on Salivary Mutans Streptococci (SMS) Levels in Children of 6-12 Years of Age: A Randomized Controlled Double Blind Study with Six-months Follow Up. J Clin Diagn Res. 2015; 9(2):Zco6-9.

22. Näse L, Hatakka K, Savilahti E, Saxelin M, Pönkä A, Poussa T, et al. Effect of long-term consumption of a probiotic bacterium,
Lactobacillus rhamnosus GG, in milk on dental caries and caries risk in children. Caries Res. 2001; 35(6):412-20.

23. Nikawa H, Makihira S, Fukushima H, Nishimura H, Ozaki Y, Ishida $\mathrm{K}$, et al. Lactobacillus reuteri in bovine milk fermented decreases the oral carriage of mutans streptococci. Int $\mathrm{J}$ Food Microbiol. 2004; 95(2):219-23.

24. Ahola AJ, Yli-Knuuttila H, Suomalainen T, Poussa T, Ahlström A, Meurman JH, et al. Short-term consumption of probioticcontaining cheese and its effect on dental caries risk factors. Arch Oral Biol. 2002; 47(11):799-804.

25. Zare Javid A, Amerian E, Basir L, Ekrami A, Haghighizadeh MH, Maghsoumi-Norouzabad L. Effects of the Consumption of Probiotic Yogurt Containing Bifidobacterium lactis Bb12 on the Levels of Streptococcus mutans and Lactobacilli in Saliva of Students with Initial Stages of Dental Caries: A Double-Blind Randomized Controlled Trial. Caries Res. 2020; 54(1):68-74.

26. Lin X, Chen X, Tu Y, Wang S, Chen H. Effect of Probiotic Lactobacilli on the Growth of Streptococcus Mutans and Multispecies Biofilms Isolated from Children with Active Caries. Med Sci Monit. 2017; 23:4175-81. 